\title{
Study Of CuZnFerrite and Ferrofluid In The Flow Injection Synthesis
}

\author{
Edie SasitoSarwodidoyo \\ Departement Refrigerasi dan Tata Udara, Politeknik Negeri Bandung \\ Bandung, Indonesia
}

\begin{abstract}
Ferrofluid is a nanoscale materials that are easy to make but of easily made these materials have physical properties that are relatively easy to change. Originally made of magnetite ferrofluid and are now able to be made in such a wide variety, and various kinds of physical properties caused. Ferrofluid will be made with basic ingredients CuZnFerrite.One process to do step wise such as Flow Injection Synthesis-FIS, to result material previously. This material is relatively toxic, but weakly. Of the various variants turns out there are two ingredients that have almost the same compound but the physical properties are extremely different. Such materials Bath088P and Bath09P.Bath088P of magnetic properties of ferromagnetic character and character Anti-ferromagnetic Bath09P.This situation is favorable for the division of tasks and responsibilities Bath088 can be directed into a ferrofluid, both cannot stable mixing, if mixing used strong magnetic to separately.
\end{abstract}

Keywords: Ferrofluid ; Flow Injection Synthesis-FIS; CuZnFerrite; Anti Ferromagnetic.

\section{INTRODUCTION}

Nanoparticles having an unstable physical properties as a result of high interaction between the particles, the growth of nano particles can form aggregates and bulky material just as the original. To limit the growth of bulky done by coating the particles with a coating (coating) or with a surfactant, and dissolving it in a certain base fluids. The molten material is formed called ferrofluid. In the medical world liquid fuel particles nanomagnetik researchers succeeded in modifying the surface of nanoparticles so that they can be used for MRI (Magnetic Resonance Imaging) and can be used for the distribution of drugs (drug delivery) in the body mabusia. $[1,2,3]$

Magnetite was first successfully synthesized by the method S.W.Charles, while maghemite with Massart method, both performed by precipitation together (co-precipitation) precursor FeCl3$6 \mathrm{H} 2 \mathrm{O}$ (ferric clorure) and $\mathrm{FeCl} 2-4 \mathrm{H} 2 \mathrm{O}$ (ferrous clorure) react with $\mathrm{NaOH}$ dissolved in water pure. $[5,6,7]$. The Average particle size is $10 \mathrm{~nm}$ magnetite $-15 \mathrm{~nm}$ and are superparamagnetic [6]. Nano materials can be a new nano material that still has the properties of magnetite but have different sizes or has a new feature that is more specific than the parent material. Examples of merger Fe304 with Mn304 (hausmanite) to Mn Fe204. [8] of the material in a way nanomagnetik mendoping magnetite with metal Mn.

Nanomagnetik material properties of the liquid material (fluid noncompresible) having ferromagnetic properties $[9,10]$.The area size and nature of the macro materials to the region size and nature of nanoscale materials described in the following scheme [11]; Of the scheme there are two kinds of fluid that can interact with the magnetic field; ferrofluid and magnetorheology (MR) fluid. Both are particlel magnetic solution in a the liquid, the difference is the size of the particles are dissolved., Ferrofluid core particle size in the range of $<100 \mathrm{~nm}$ while the MR fluid particle size in the range of $1000 \mathrm{~nm}$. Ferrofluid particles have a particle 
size distribution are stabilized by the surfactant layer, among others; amphiphilic molecules, such as oleic acid (oleic acid) and sodium aerosol in-2ethylhexyl-sulfosuccinate). [12] , Preparation ferrofluid materials exist two phases; 1.tahap nanomagnetik particle preparation, 2. Phase surfaktansi and dispersion of nano- particles in a liquid base as appropriate. [13].

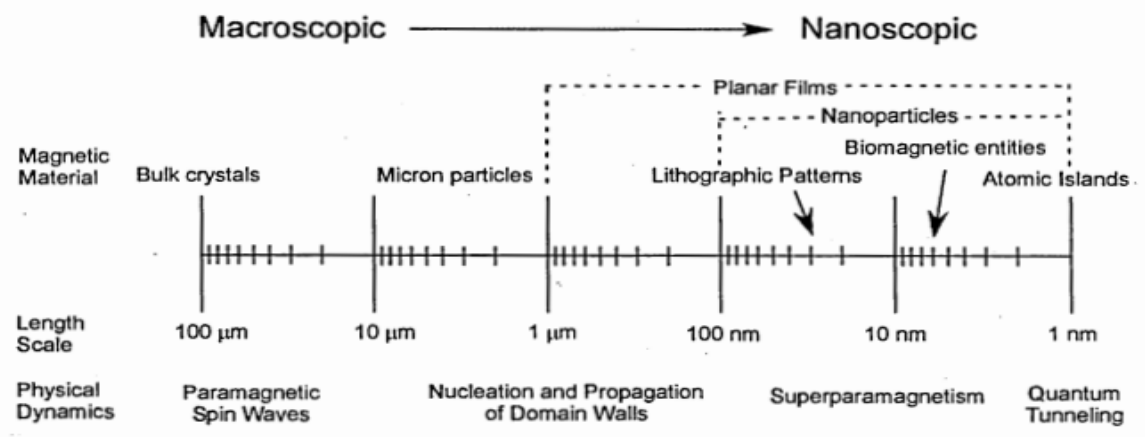

Figure 1 scheme macro region to region nano [11].

The particle size of the core ferrofluid experiencing different growth for among other things, the effect of external magnetic fields can accelerate the process of growth of core particles. [14].

The reasons for the changing nature of the chemical properties of small particle physics is, the smaller the particle size may cause some of the following improvements [2,3,14,15]; among other things, an increase in the number fraction of the atoms, the increase in the fraction of the surface energy and chemical potential and increase the interaction between the surface of the nano partikel.Partikel have allowed to grow to be larger during the synthesis process. Speed the process of growth of nanoscale materials with the core particles is still very small will be very easily influenced by physical properties and environmental conditions [14] If the environmental conditions carefully guarded and process fluctuations can be maintained relatively stable it will obtain nanoparticles with a size relatively uniform (monodisperse) or in other words a narrow distribution of particle size [15]. In the intensive study of nanoparticle preparation that can not be separated from ferofluidisasi to suppress the particle growth process conducted intensively by NASA in 1969. [17,18,19].

Ferrofluid with a non-uniform magnetic properties will have an impact on the limited use of the ferrofluid in high technology, such as; medical treatment, microwave absorber, magnetic bearing, etc. From this background, the thought of renewing coprecipitasi process that can produce yields that are likely to monodisperse. Copresipitasi synthesizing process performed by first draining the raw material metal chloride (ferro ferric) chloride and alkaline materials $[20,21,22,23,24]$ at a certain speed in a single reactor.

The use of the surfactant layer serves to limit pertumbihan oleid acid particles, the materials used are common materials used, such as acid olead (Oleid Acid), it matters related to the process surfaktansi done with limited analysis. Preparation steps are Ferrofluid using the apparatus Flow Injection Synthesis -FIS.

There were washing yield of FIS reactor with liquid aqua DM Until the $\mathrm{pH}$ of the system solution approached 7.00, for 20 grams of core samples require $1 / 2$ gallons of aqua DM. Separation/purification ferrofluid of $\mathrm{NaCl}$ use acetone and addition of acid surfactans oleid, the carrier fluid (oil) followed by the mixing process. The provision of carrier fluid that does not 
reject the presence of air core surfaktans , the surfactans citric acid in water, enter Ferrofluid core and do stirring

\section{EXPERIMENT}

Ferrofluid is described in the form of a round or oval sphere which is accompanied by a small circle tail (hydrophobic, hydrophilic) to describe a layer of surfactant (Surface active substance) as shown below; [12].

The synthesis process Nanomagnetik As Core ferrofluid particles Ferrofluid synthesis process by the method of co-precipitasi more emphasis on the process of forming core particles ferrofluid. For magnetite core process of co-precipitasi occur as a result of a process of salting $\mathrm{FeCl} 2.4 . \mathrm{H} 2 \mathrm{O}, \mathrm{FeCl} 3.6 \mathrm{H} 2 \mathrm{O}$ with $\mathrm{NaOH}$ or $\mathrm{NH} 4 \mathrm{OH}$ yielding $\mathrm{Fe} 3 \mathrm{O} 4$ (magnetite) which is followed by the deposition process yield. [2,13]. The process of dissolution of colloidal particles and the possibility agregratasi process (precipitation) indicates that the ferrofluid colloidal system instability solubility may their unstable process. Ferrofluid solution system is stable if the solution free from the influence of the terrain will soon return to normal. In the process of synthesizing nanomagnetik stabilasi ferofluidisasi co-precitasi method obtained by conditioning the $\mathrm{pH}$ of the oceans $[17,18,19]$.

Nanomagnetik particle formation begins with the emergence of point nuklius. Nukliasi process occurs after the collision (collision) atoms precursor, followed by refinement of crystal structures form [3]. The crystal structure is formed endeavored not allow the oxidation and reduction processes take place. To the reactor requires a process insulation against the presence of oxygen, by bubbling Nitrogen, Argon, ammonia or in an airtight reactor, or by adding HCL in each of each solution of chloride salts. The $\mathrm{pH}$ control, temperature control process, typical iron salt that is used and the presence of oxygen during the synthesis process will affect the particle size (particle size) and particle size distribution. [31]

In the event of simultaneous deposition process also occurs magnetisasi.Pada magnetization process is done heating at 1000C for 1 hour, followed by washing process. Control of the process is done by conditioning the $\mathrm{pH}$ of the solution at the numbers 11-13. The surfaktantion process and dispersion particles into the liquid carrier are generally done after the process of purification and washing of nano particles. The surfaktantion process intended to limit the growth process the particles formed aglomerasioses, so that the particles are monodisperse can be maintained. The especial ferrofluid that is used for medical purposes other than the core particles should be of superparamagnetic but has stability and less toxic, eg MnFerrite which serves as an MRI contrast agent and hyperthermia cancer treatment [33].

\subsection{Preparation Material Co-Precipitation of Ferrite [18]and CuZnFerrite}

The chemical react $\mathrm{MeFe} 2 \mathrm{O} 4$ with $\mathrm{Me}$ as $\mathrm{Fe}, \mathrm{Cu}$,and $\mathrm{Zn}$ it means the chemical of the $\mathrm{CuZnFe}_{2} \mathrm{O}_{4}$ Can be expressed as:

a. Generally react equation such hidrat process.

$$
\begin{aligned}
& (1-\mathrm{x}) \mathrm{Cu}^{2+}+\mathrm{xZn}^{2+}+2 \mathrm{Fe}^{3+}+8 \mathrm{OH}^{-} \rightarrow \\
& (1-\mathrm{x}) \mathrm{Cu}(\mathrm{OH})_{2} \cdot \mathrm{xZn}(\mathrm{OH})_{2} \cdot 2 \mathrm{Fe}(\mathrm{OH})_{3} \downarrow
\end{aligned}
$$

b. Generally react equation such Ferritation process.

$$
\begin{aligned}
& (1-\mathrm{x}) \mathrm{Cu}(\mathrm{OH})_{2} \cdot \mathrm{xZn}(\mathrm{OH})_{2} \cdot 2 \mathrm{Fe}(\mathrm{OH})_{3} \text { aq } \uparrow \mathrm{t}^{0} \rightarrow \\
& \mathrm{Cu}_{(1-\mathrm{x})} \mathrm{Zn}_{\mathrm{x}} \mathrm{Fe}_{2} \mathrm{O}_{4} \cdot \mathrm{nH}_{2} \mathrm{O}+(4-\mathrm{n}) \mathrm{H}_{2} \mathrm{O}
\end{aligned}
$$

When the mixing process the salt and alkaline, at the physical following Nucleation and growth such as Lamer and Dinagar teorema [5]. To restrict oxide process like ; fresh raw material, 
flowing of $\mathrm{N}_{2}, \mathrm{CO}_{2}$, or Argon gas.

Ferrite Core Particle Preparation Mex Fe (3-x) 04, reactants; MeCl2.6H2O, could Me is a metal of $\mathrm{Ni}, \mathrm{Mn}, \mathrm{Zn}, \mathrm{Cu}, \mathrm{FeCl} 2.4 \mathrm{H} 2 \mathrm{O}, \mathrm{FeCl} 3.6 \mathrm{H} 2 \mathrm{O}, \mathrm{HCl}, \mathrm{NaOH}$.

The reaction process;

Preparation of the Particle core Ferrite $\mathrm{Me}_{\mathrm{X}} \mathrm{Fe}(3-\mathrm{x}) \mathrm{O} 4$

Reaktan; $\mathrm{MeCl}_{2} .6 \mathrm{H}_{2} \mathrm{O}$, Me As ; $\mathrm{Ni}, \mathrm{Mn}, \mathrm{Zn}, \mathrm{Cu}$

$\mathrm{FeCl} 2.4 \mathrm{H}_{2} \mathrm{O}, \mathrm{FeCl} 3.6 \mathrm{H} 2 \mathrm{O}, \mathrm{HCl}, \mathrm{NaOH}$. Reaction Process ;

$\mathrm{FeCl} 2.4 \mathrm{H}_{2} \mathrm{O}+\mathrm{FeCl}_{3} .6 \mathrm{H}_{2} \mathrm{O}+\mathrm{NaOH}+\mathrm{MeCl}_{2} .6 \mathrm{H}_{2} \mathrm{O} \rightarrow(\mathrm{MeO})\left(\mathrm{Fe}_{2} \mathrm{O} 3\right) \downarrow+\mathrm{NaCl}+\mathrm{H}_{2} \mathrm{O} \mathrm{FeCl}_{2}+$ $\mathrm{FeCl}_{3}+\mathrm{MeCl}_{2}+\mathrm{NaOH}+\mathrm{H}_{2} \mathrm{O} \rightarrow \mathrm{Fe}(\mathrm{OH}) 2+\mathrm{Fe}(\mathrm{OH}) 3+\mathrm{Me}(\mathrm{OH}) 2+\mathrm{NaCl}+\mathrm{H}_{2} \mathrm{O}$.

For $\mathrm{Me}$ as $\mathrm{Cu}$ and $\mathrm{Zn}$, Yield ; $\mathrm{Cu}_{(1-\mathrm{x})} \mathrm{Zn}_{\mathrm{x}} \mathrm{Fe}_{2} \mathrm{O}_{4}$

The reaction equation is;

$2 \mathrm{FeCl}_{2} \cdot 4 \mathrm{H}_{2} \mathrm{O}+4 \mathrm{FeCl}_{3} \cdot 6 \mathrm{H}_{2} \mathrm{O}+3 \cdot \mathrm{x} \mathrm{ZnCl}_{2}+3(1-\mathrm{x}) \cdot \mathrm{CuCl}_{2} \cdot 2 \mathrm{H}_{2} \mathrm{O}+22 \mathrm{Na}(\mathrm{OH}) \rightarrow \mathrm{Zn}_{\mathrm{x}} \mathrm{Cu}_{(1-\mathrm{x})} \mathrm{Fe}_{2} \mathrm{O}_{4}$

Adiabatic reactors, serves as a chemical reactor that will condition the reaction system is not affected by the outside temperature so that the temperature terrekam a chemical reaction in the temperature of the material forming process.

\subsection{ZnCuFerrite Raw Materials.}

The raw material comes from the chemical analytical consisting of metal chloride salts and alkaline bases such as tabulated in the Table 2 as follows;

Table 2, The Raw Material Contain of the Yield.

\begin{tabular}{|c|c|c|c|c|c|c|c|c|c|c|}
\hline & \multicolumn{2}{|c|}{$\mathrm{ZnCl} 2$} & \multicolumn{2}{|c|}{$\mathrm{CuCl}_{2 .} 2 \mathrm{H}_{2} \mathrm{O}$} & \multicolumn{2}{|c|}{$\mathrm{FeCl} 2.4 \mathrm{H} 2 \mathrm{O}$} & \multicolumn{2}{|c|}{ FeCL3.6H2O } & \multicolumn{2}{|c|}{$\mathrm{Na}(\mathrm{OH})$} \\
\hline & Mol & gram & Mol & $\begin{array}{l}\text { Gra } \\
\text { m }\end{array}$ & Mol & $\begin{array}{l}\text { Gra } \\
\text { m }\end{array}$ & Mol & $\begin{array}{l}\text { Gra } \\
\text { m }\end{array}$ & Mol & $\begin{array}{l}\text { Gra } \\
\mathrm{m}\end{array}$ \\
\hline Bath04P & 0,024 & 3.27 & $\begin{array}{l}0,03 \\
6\end{array}$ & 6.13 & $\begin{array}{l}0.0 \\
4\end{array}$ & 7.95 & 0.08 & $\begin{array}{l}21.6 \\
3 \\
\end{array}$ & 0.44 & 17.6 \\
\hline Bath06P & 0.036 & 4.90 & $\begin{array}{l}0.02 \\
4\end{array}$ & 4.09 & $\begin{array}{l}0.0 \\
4\end{array}$ & 7.95 & 0.08 & $\begin{array}{l}21.6 \\
3\end{array}$ & 0.44 & 17.6 \\
\hline $\begin{array}{l}\text { Bath078 } \\
\text { P }\end{array}$ & 0.047 & 6.38 & $\begin{array}{l}0.01 \\
3\end{array}$ & 3.22 & $\begin{array}{l}0.0 \\
4\end{array}$ & 7.95 & 0.08 & $\begin{array}{l}21.6 \\
3\end{array}$ & 0.44 & 17.6 \\
\hline $\begin{array}{l}\text { Bath088 } \\
\text { P }\end{array}$ & 0.053 & 7.20 & $\begin{array}{l}0.00 \\
7\end{array}$ & 1.22 & $\begin{array}{l}0.0 \\
4\end{array}$ & 7.95 & 0.08 & $\begin{array}{l}21.6 \\
3\end{array}$ & 0.44 & 17.6 \\
\hline Bath09P & 0.054 & 7.36 & $\begin{array}{l}0.00 \\
6\end{array}$ & 1.02 & $\begin{array}{l}0.0 \\
4\end{array}$ & 7.95 & 0.08 & $\begin{array}{l}21.6 \\
3\end{array}$ & 0.44 & 17.6 \\
\hline
\end{tabular}

\section{Material Preparation.}

The material mixed dropwise until completion, stirring constantly. Furthermore, the precipitation and filtration until the $\mathrm{pH}$ close to 7 . Drying is done by heating to 80 degrees more than 8 hours, after cleaning, the material is crushed in a mortar and screened ferrite powder. do testing. To do ferrofluid making additions oleid after settling and filtering to $\mathrm{pH}$ close to 7. Do the processes up to 6 samples, from sample to Bath04P Bath09P.

Result of the reactions were sampel Bath04 to Bath088P give liquid dark colour and give respons and atract by magnetic. Bath09 no atractive by magnetic and tend to reject the existence of of magnetic. 


\section{DISCUSSION}

3.1 Estimation of Particle Size and Growth Rate of Particle Material Cu-ZnFerrite. In connection with the approach of the estimated Avrami that the enforceability of the state of uniform temperature (isothermal) having linearity only in the area of formation yield of about $3 \%$, while the fraction of the yield depends linearly with temperature $\mathrm{T}$ [Kuo et al, 2005] the growth of the material allows to have more than one kind of growth among others; Avrami model of particle growth (Isothermal) with a linearity of about 3\% yield formation and particle growth models Avrami Ozawa.

Given an isothermal process is only about $3 \%$, the calculation can be disallowed by simply estimating the particle growth in non-isothermal systems. To determine the Avrami constant at a constant rate of change of temperature, growth rate constant $\mathrm{k}$ is expressed by the equation:, $\mathrm{v}$ particle growth rate. $\mathrm{N}$ number of particles $=\Sigma$ moles $\mathrm{x}$ Avogadro's number. The faction yield determined in a steady state of $4.18667 \mathrm{~N} * \mathrm{v} 3$.

The number of samples so that the mole 0:06; $\mathrm{N}=0: 06$ mole $=0.06 \mathrm{x} 60221023=0.156572 \mathrm{x}$ 1023 particles. Given $\mathrm{k}=0,656 \mathrm{x} 1023 \mathrm{xv} 3$ then $\mathrm{v}=\{\mathrm{k} /(0,656 \times 1023)\} 1 / 3=\mathrm{k} 1 / 3 /$ $(4,033 \times 107)$. $K$ value is determined from an experiment by using the software Ms.Excel can be calculated growth rate and particle size as table 8 below.

Table 3. Estimated Growth Rates Cu-Zn Ferrite Particle

\begin{tabular}{|c|c|c|c|c|c|c|}
\hline \multirow{2}{*}{ No } & \multirow[b]{2}{*}{ Parameter } & \multicolumn{5}{|c|}{ Sample Code } \\
\hline & & Bath 04P & Bath 06P & Bath78P & Bath088P & Bath9P \\
\hline 1 & $\begin{array}{l}N \\
\text { partikel shape }\end{array}$ & 1,1843 & 1,3909 & 1,4315 & 1,776 & 0,9891 \\
\hline 2 & $\begin{array}{l}\mathrm{k} \text {, reaction } \\
\text { rate constant }\end{array}$ & 19,611 & 29,58 & 26,4058 & 0,05127 & 18,395 \\
\hline 3 & $\mathrm{k}^{1 / 3}$ & 2.427802 & 2.866763 & 1.342575 & 0.848093 & 2.443534 \\
\hline 4 & $\begin{array}{c}\mathrm{v}=\left\{\mathrm{k}^{1 / 3} / 4,033\right\} \times 10^{-} \\
7 \\
\text { Particle growth }\end{array}$ & $\begin{array}{c}60 \\
\mathrm{~nm} / \mathrm{sec}\end{array}$ & $\begin{array}{c}71 \\
\mathrm{~nm} / \mathrm{sec}\end{array}$ & $\begin{array}{c}33 \\
\mathrm{~nm} / \mathrm{sec}\end{array}$ & $\begin{array}{c}21 \\
\mathrm{~nm} / \mathrm{sec}\end{array}$ & $\begin{array}{c}61 \\
\mathrm{~nm} / \mathrm{sec}\end{array}$ \\
\hline 5 & $\begin{array}{l}\mathrm{T}_{\text {settle(second) }} \\
\text { Settling Time }\end{array}$ & 30 & 29.7 & 29.1 & 20 & 39 \\
\hline 6 & $\begin{array}{c}\text { D [nm] } \\
\text { (Diameter Partikel) }\end{array}$ & $\begin{array}{l}1800 \\
(1,8 \\
\mathrm{um})\end{array}$ & $\begin{array}{c}2100 \\
(2,1 \\
\text { um })\end{array}$ & $\begin{array}{l}970 \\
(0.97 \\
\text { um) }\end{array}$ & $\begin{array}{c}420 \\
(0,42 u \\
m)\end{array}$ & $\begin{array}{l}2360 \\
(2,36 \\
\text { um })\end{array}$ \\
\hline
\end{tabular}

Parameter versus diameter graph is described as follows

This is where the true center of our attention. Visible striking difference between Bath088P with Bath09P. From the composition of the compound both have a very thin difference, but the difference is the diameter that forms the highest. This is where the true center of our atention. It appears that at bath088P has the lowest rate of reaction $(0.05127)$, while the speed of the reaction at bath078 is 26.4058 and at bath088P is 18.395 
The highest entropy estimate of 9.62 [J / mol K] happened Bath09P samples while the lowest estimate of the entropy of 8.67 [J / mol K] occur in the sample bath06P and bath088P. Materials to the entropy of the highest such samples bath09P will have a level of stability that is the lowest, whereas materials with entropy lowest such bath06P and 088P will have a level of stability that is the highest, then the entropy materials sampelbath 088P and the sample material bath09P have a level of stability is very different though from the side raw material almost no different.

In the sample bath078P, bath088P, and bath09P occur the different positive entropy or the test material decrease in temperature. While the sample bath04, bath06 there is a difference of negative entropy or an increase in temperature. Entropy highest sample 9.62 [J / mol K] happened bath09P sample. In physics among the existing materials of the most unstable is the bath09 material that has the highest entropy.

In connection with the estimation approach Avrami that the enforceability of the state of uniform temperature (isothermal) having linearity only on yield formation surrounding area $3 \%$, while the yield fraction depends linearly with temperature $\mathrm{T}$ [Kuo et al, 2005] the growth of the material allows to have more than one kind of growth, among others; Avrami model of particle growth (Isothermal) with a linearity of about 3\% yield formation, growth models Avrami Ozawa. Given an isothermal process is only about 3\%, the calculation can be disallowed by simply determining the particle growth in non-isothermal systems. Avrami constants to determine the rate of change of temperature constant $\mathrm{k}$.

In the process of forming bath sample produce material particles number $\mathrm{N}=0: 06$ mole $=$ $0.06 \times 60221023 \times 1023$ particles $=0.1565722 .48012 \Phi=\{\}^{*} \mathrm{k} 1 \times 10-8 / 3$. Assuming the cube-shaped particles, particle growth rate estimates can be calculated estimation using Avrami equation $\mathrm{n}=4$ / 3xПx N x L3 where $\mathrm{N}=$ number of particles partike and L length.

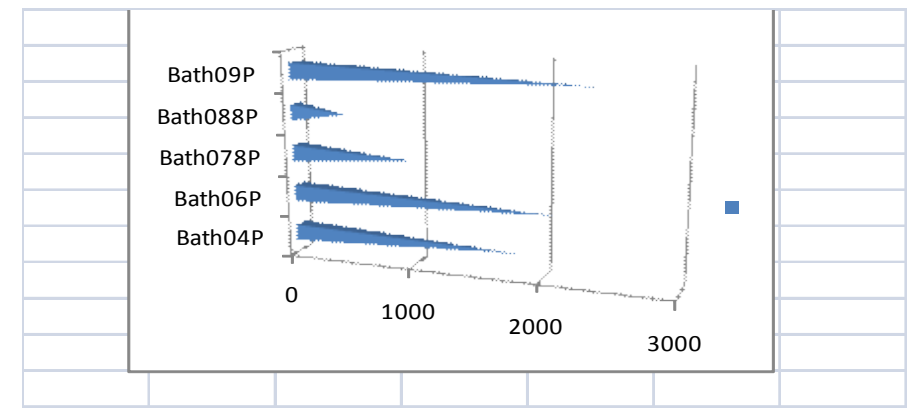

Figure 2. The series of Bath Sample Diameter (nm).

Then it can be predicted that Bath088P particles are particles which easily preyed upon by opponents reaction.

The existence of particles Bath088P relatively easily lost, in which the reaction rate is low 21 $\mathrm{nm} / \mathrm{sec}$ and most setling time low $(20 \mathrm{sec})$ while others have an average settling time $31 \mathrm{sec}$. The rate of growth is highest in the particle formation process Fisbath06 ie 2:39 $\mathrm{nm} /$ second, while the slowest rate of growth of particles occurs in the process of forming Fisbath088P 1:05 nm / secod. In Bath078 sample rate of growth of 1:14 nm / sec. Time calculated from the full process from starting the process in which the fraction of the yield of $0 \%$ to yield $100 \%$ where the $\mathrm{pH}$ of the solution is considered steady. Utuk process time $33 \mathrm{sec}$ obtained Avrami particle size Ozawa 33.nm. 
Based on the nature of the $\mathrm{Zn} \mathrm{2+}$ cations in spinel crystals that control the properties ferromagnetic material, ferrite material and entropy values, can be compared between one ingredient. Enthalpy of formation of the calculation results in Table 4.1 shows that the bath09 value formation enthalpy and entropy of the highest material. Thermodynamically hinted that the material has a stable crystal bath 09P lowest. In general, the theoretical particle size material CuZnFerrite $=49.24 \mathrm{~nm}$ with the rate of formation of the mean $=1.6[\mathrm{~nm} / \mathrm{sec}]$.

Characterization using a particle diameter measuring tool Particle Size Analyser (PSA) capable of about $1 \mathrm{um}$, and characterization using a measuring instrument magnetism Permagraf to determine the magnetic properties of materials such as; diamagnetic, paramagnetic, ferromagnetic, ferromagnetic etc. The second compilation of materials characterization shaped graph so if tabulated in the table will be obtained portrayal of characters simultaneously both material characterization and Permagraf PSA initially shaped numeric data in two columns, which can be directly converted into a graph using excel processor. PSA graph the volume fraction of the material particle diameter, while the graph magnetism in the form of a graph histerograf as a result of magnetization $\mathrm{J}[\mathrm{T}]$ to the strength of the magnetic field $\mathrm{H}$ [kA / meter] outside material influence.

Magnetic characterization done to get an initial picture of the influence of cations $\mathrm{Zn} 2+, \mathrm{Cu} 2+$ and Fe 2+. The higher the concentration of ions Zn 2+ and Fe 2+. High magnetitation properties of materials. The higher the concentration of $\mathrm{Cu} 2+$ ions will affect the electrical properties of materials and reduced magnetic properties.

The nature of the material is also influenced by the particle size (particle size) material, the smaller the particle size of the material, the material will tend to have the magnetic properties, which are shown in graphical form histersis increasingly slim magnetization of the material.

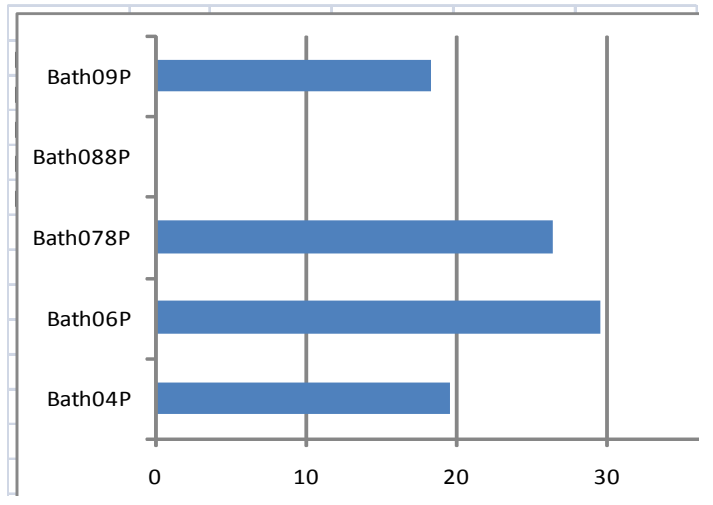

Figure 3. Every bath activation position

In the bath06P seen reaction constants and constants highest growth ie $\mathrm{k}=29.8$ and $\mathrm{v}=71 \mathrm{~nm}$ / sec. contrary to bath088P, meaning that if the two meet there will be no unification.

Bath088P core influence on the core else especially adjacent compound (bath09P) is the core tends trapped against larger core, especially if it appears that the core Bath088P more aggressive than the core trap.

The highest entropy estimate of 9.62 [J / mol K] happened Bath09P samples while the lowest estimate of the entropy of 8.67 [J / mol K] occur in the sample bath06P and bath088P. Materials to the entropy of the highest such samples bath09P will have a level of stability that is the lowest, whereas materials with entropy lowest such bath06P and 088P will have a level of stability that is the highest, then the entropy materials sample bath 088P and the sample 
material bath09P have a level of stability is very different though from the side raw material almost no different.

In the sample bath078P, bath088P and bath09P happen the difference entropi is positive or the test material decrease in temperature. While the sample bath04, bath06 there is a negative difference.

In general, behave as soft magnetic materials such as bath088P with hysteresis relatively sharp and graphically magnetic coercivity relatively little material. There coercivity maximum magnetic magnetization regions. Bath088 hysteresis and 085 models are the models hysteresis for magnetic materials which has high response to changes in magnetic properties. So it has the ability as a high-frequency magnetic core.

\subsection{Entropy Sample}

Table 7. Estimated Energy Materials Forming CuZnFerrite

\begin{tabular}{|l|l|l|l|l|l|}
\hline & $\begin{array}{l}\text { Drivin } \\
\text { g } \\
\text { energy } \\
\text { [J / } \\
\text { mo] }\end{array}$ & $\begin{array}{l}\text { The reaction } \\
\text { enthalpy [J / } \\
\text { mol] } \\
{[\text { Kcal / mol] }}\end{array}$ & $\begin{array}{l}\text { Estimated } \\
\text { Energy [J / } \\
\text { mole] } \\
\text { (kcal/mole } \\
\text { ) }\end{array}$ & $\begin{array}{l}\text { Temp. } \\
\text { Average }\end{array}$ & $\begin{array}{l}\text { Entropy } \\
\text { [J / mol K] } \\
\text { (X 10-3 Cal / } \\
\text { mol K) }\end{array}$ \\
\hline Bath 04P & 540 & $2180.92(0)$. & $\begin{array}{l}(0.65) \\
2627\end{array}$ & 303 & $(2.145) 8.97$ \\
\hline Bath 06P & 400 & $227.01(0.53)$ & $\begin{array}{l}(0.63) \\
2720\end{array}$ & 302.7 & $(2.079) 8.67$ \\
\hline Bath 078P & 646 & $2181(0.52)$ & $\begin{array}{l}(0.68) \\
2827\end{array}$ & 303 & $(2.244) 9.33$ \\
\hline Bath 088P & 400 & $2184(0.52)$ & $(0.62) 2584$ & 298 & $(2.080) 8.67$ \\
\hline Bath 09P & 736 & $2178(0.52)$ & $\begin{array}{l}(0.70) \\
2914\end{array}$ & 303 & $(2,310) 9.62$ \\
\hline
\end{tabular}

Entropy highest sample 9.62 [J / mol K] happened in bath09P sample. In physics among the existing materials of the most unstable is the bath09 material that has the highest entropy, and most stable is the Bath 088P

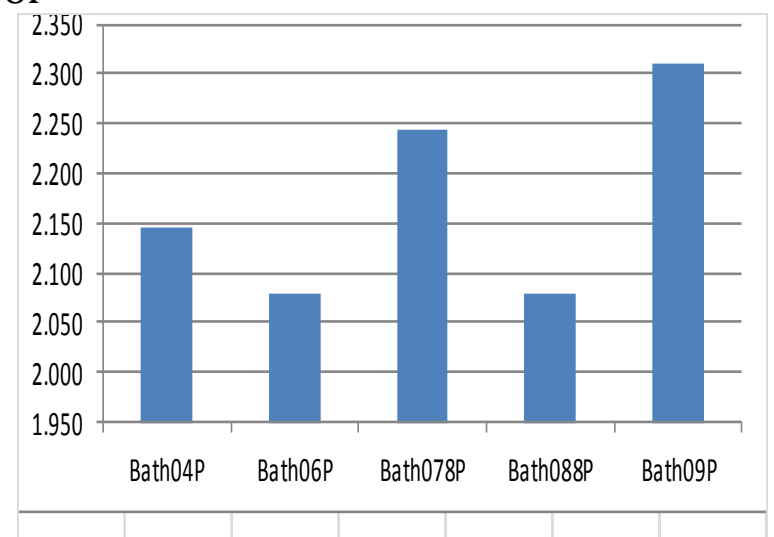

Figure4. Entropy of Sample Bath.

Magnetic test use permagraf. Bath088P as Soft Ferromagnetic and Bath09P as Anti Ferromagnetic such as the following figure.

Particle size Fisbath06P sample average 18.79 um, is a soft ferromagnetic with histeresis relatively linear approach and Magnetization material is relatively small so the tendency leads to the paramagnetic properties. But with an average diameter that is far from the nano particle size soft magnet properties more dominant than paramagnetic. 


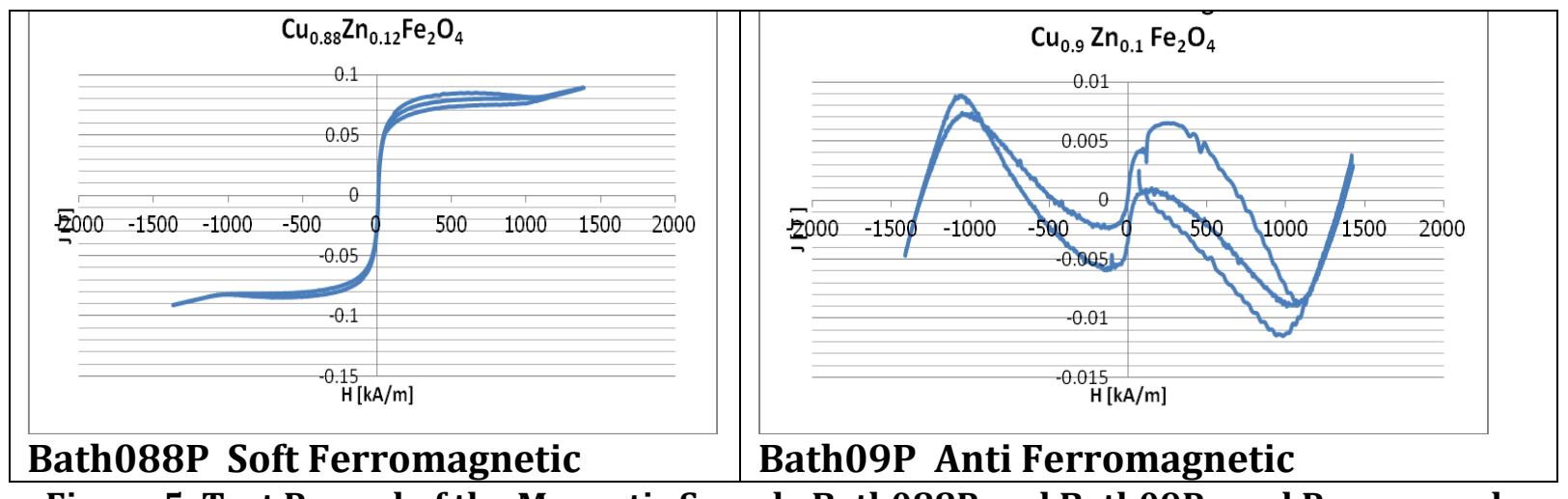

Figure 5. Test Record of the Magnetic Sample Bath088P and Bath09P used Permagraph.

Bath04P to Bath09P usually as magneto rheology (MR) fluid, but Bath088P have particle diameter about $0.42 \mathrm{um}$ tend to $0.1 \mathrm{um}$ and have magnetic behavior, like as Ferrofluid. Although the respons of Bath088P have 10 times the magnetic strength but almost like respons of $1 \mathrm{x}$ Bath09P. This condition the liquid material may in twu condition. For mixing make striking difficult to sparately.

\section{CONCLUSION}

1. Flow Injection Technique Synthesis-FIS is a co-precipitation synthesis method structured, ie, monitor, store, the parameters $\mathrm{pH}$, temperature $\mathrm{T}[\mathrm{K}]$, and the processing time $\mathrm{t}$ [sec], so as to obtain the data aquisisi system parameters quick process. With chloride raw materials $\mathrm{FeCl} 2.4 \mathrm{H} 2 \mathrm{O}, \mathrm{FeCl} 3.6 \mathrm{H} 2 \mathrm{O}, \mathrm{ZnCl} 2, \mathrm{CuCl} 2.2 \mathrm{H} 2 \mathrm{O}$ and $\mathrm{NaOH}$, FIS technique capable of producing $\mathrm{Zn}$-Cu Ferrite. With FIS process parameters obtained estimates the average energy-forming material at room temperature of $0.66 \mathrm{kcal} / \mathrm{mol}$. This value it is approaches the thermodynamic enthalpy literature references presented by A. Navrosky and Kleppa 1967. Analysis of the kinetics of the particle can be estimated theoretically CuZnFerrite material particle size of about 1.53 um.with growth rate of 50 [nm / sec]

2. Sample Bath088P has the highest possibility to be used as material Ferrofuid with the properties of the smallest particles and the least reactive and Soft Ferromagnetic. Diferent with Bath09P there is no reaction in magnetic. In the chemical reaction between compounds with compounds Bath088P bath09P difference is very little raw material components, but provide a striking difference in physical properties. This proves that chemical compounds have a very important role in the properties of the material.

3. Mixing between of the Bath088P with the Bath09P essentially simple case, given similar compounds, but it is easy separation, ie by bringing the magnets are strong. Moreover, already in the form of Ferrofluid easily separated. 


\section{REFERENCES}

[1] Skomski.R,2003, Topical Review Nanomagnetics, Department of Physics and Astronomy and Center for Materials Research and Analysis, University of Nebraska, Lincoln, NE 68588, USA, J. Phys.: Condens. Matter 15 (2003) R841- R896

[2] Sundaresan.A,NANOMAGNETISM,Chemistry and Physics Materals Unit,Jawaharal Nehru Centre For Advance Scientific Research ,Bangalore 560064.

[3] Ahmadi, Madaah hosseini and and masoudi,2011,Avrami Behavior Of Magnetite Nanoparticles, Formation In Co-Precipitation Process, Department of Materials Science and Engineering, Sharif University of Technology, P.0. Box1458889694, Tehran, Iran

[4] Berger Patricia ,Preparation and Properties of an Aqueous Ferrofluid W,Department of Chemistry, Southern Oregon University, Ashland, OR 97520 Nicholas B. Adelman, Katie J.Beckman, Dean J.Campbell, $\dagger$ and ArthurB. Ellis*Department of Chemistry, University of Wisconsin Madison, Madison, WI53706; *ellis@chem.wisc.edu George C. LisenskyDepartment of Chemistry, Beloit College, Beloit, WI 53511.

[5] Urreta.H.1, Murillo.3 ,Bou-Ali.M.M2 . Overview of The Ferrofluids Synthesis For Mechanical Applications , 1 IDEKO Technology Centre, Mechanical Engineering Department. Elgoibar, Spain. 2 MGEP Mondragón Goi Eskola Politeknikoa,Mondragón, Spain. 3 CIDETEC Centre for Electrochemical Technologies. San Sebastian, Spain.

[6] Lin Chia-Lung, C Lee hia-Fen 1, Chiu Wen-Yen, 11 July 2005.,Preparation And Properties Of Poly(Acrylic Acid) Oligomer Stabilized Superparamagnetic Ferrofluid, Department of Materials Science and Engineering, National Taiwan University, Taipei, Taiwan, Republic of China Received 20 February, accepted 9 May 2005, Available online.

[7] Swiatkowska Zaneta, Kawaguchi Kenji, Wang, Hongqiang Katou Yukiko, Koshizaki Naoto,2011, Controlling exchange bias in Fe304/FeO composite particles prepared by pulsed laser irradiation, Swiatkowska- Warkocka et al. Nanoscale Research Letters 2011, 6:226. http://www.nanoscalereslett.com/content/6/1/226

[8] Bacri J.C, Perzynski,1994,Colloidal Stability and Transport Properties of Ferrofluid, Laboratoire d'Acoustique et optique de la Matiere Condenseet, Universite' Piere et Marie Tour, Paris Cedex, France.

[9] Seval Genç,2002, SYNTHESIS AND PROPERTIES OF MAGNETO RHEOLOGICAL (MR) FLUIDS, University of Pittsburgh, Submitted to the Graduate Faculty shool of Engineering in partial fulfillme of the requirements for the degree of Doctor of Philosophy

[10] Zalich Michael Andrew ,2005, PHYSICAL PROPERTIES OF MAGNETIC MACROMOLECULE METAL AND MACROMOLECULE-METAL OXIDE NANOPARTICLE COMPLEXES, Dissertation submitted to the faculty of the Virginia Polytechnic Institute and St University in partial fulfillment of the requirements for the degree of Doctorof Philosophy In Chemistry.

[11] Vestal Christy Reann,2004,Magnetic Couplings And Superparamagnetic Properties Spinel Ferrite Nano Particles ,Georgia Institut of Technology, a Dissertation Presented to The Academic Faculty.

[12] Scherer.C and Figueiredo Neto , A. M.

July, 2005, Ferrofluids: Properties and Applications, Instituto de Física, Universidade Federal do Rio Grande doSul 90570-100, Porto Alegre, RS, Brazil aaInstituto de Física, Universidade de São Paulo, Caixa Postal 66318, 05315-970, São Paulo, SP, Brazil Received on 28.

[13] Charles Stuart W. The Preparation of Magnetic Fluids, Department of Chemistry, University of Wales, Bangor, Gwynedd LL57 2UW, UK. Liquids Research Limited, Mentec, Deiniol Road, Bangor, Gwynedd LL57 2UP, UK 
[14] Racuciu M. . Creang b.,2005, SYNTHESIS AND RHEOLOGICAL PROPERTIES OF AN AQUEOUS FERROFLUID, Jounral of Optoelectronics and Advanced Materials Vol. 7, No. 6, December 2005,a, Gh. C lug rub "Lucian Blaga" University, 10, Victoriei Blvd, 550012, Sibiu, Romania, a Faculty of Physics, "Al. I. Cuza" University, 11A Blvd. Copou, Iasi, Romania, b"Gh. Asachi”. University, Physics Department, Bd. D. Mangeron, 68, Iasi, Romania.

[15] Gubin S P, Koksharov.Yu A, Khomutov G B, Yurkov. G Yu,2005, Magnetic nanoparticles: preparation, structure and properties, Russian Chemical Reviews 74 (6) $489 \pm 520$ (2005), Russian Academy of Sciences and Turpion Ltd.

[16] Chau .N. 1, Thuan N.K. 1. Minh2, . Luong1, D.L., N.H*,2008, Effects of Zn content on the magnetic and magnetocaloric properties of Ni-Zn ferrites, Center for Materials Science, College of Science, VNU, 334 Nguyen Trai, Hanoi, Vietnam Department of Solid State Physics, College of Science, VNU, 334 Nguyen Trai, Hanoi, Vietnam, VNU Journal of Science, Mathematics - Physics 24 (2008) 155-162

[17] Kaiser Robert, Rosenwig Ronald E, August 1969, STUDY OF FERROMAGNETIC LIQUID, AVCO CORPORATION, Lowell, Mass. For National Aeronautics And Space Administration Washington, D. C.

[18] Cherkezova.Z, Zeleva, 2011,Study of Nanosized Ferrite Materials Prepared by Co-Precipitation Method,Institut of Catalysis Bulgarian Academy of Sciences, Sofia, Bulgaria, Seventh National Conference on Chemistry.

[19] Mohapatra* and S. Anand**, 2010 ,Synthesis and applications of nano-structured iron oxides/hydroxides - a review ,Institute of Minerals and Materials Technology,

Bhubaneswar, Orissa, INDIA ** Presently Murdoch University, Western Australia $\quad{ }^{* E}$-Mail: mamatamohapatra@yahoo.com

[20] Purohit atish B1, Lapalikar S. R.2, Pare Sachin 1 and Jain Vikas 1, Characteristics of ferro fluid, Mechanical Engineering Department, SGS Institute of Technology and Science, Indore-452002, India 2 Principal, Indore Institute of Science and Technology, Indore-452003, India ,purohitsb_55@yahoo.co.in. Indian Journal of Science and Technology, Vol. 4 No. $11 \quad$ (Nov 2011).

[21] Lopez. S Javier A2010 ,SYNTHESIS AND CHARACTERIZATION OF Fe304 MAGNETIC NANOFLUID , Revista Latinoamericana Metalurgia Materiales ,Thin Films Group, Universidad del Valle, Cali, Colombia. E-mail: javierlo21@gmail.com

[22] Charles S W,1992, MAGNETIC FLUIDS (Ferrofluids), Department of Chemistry, University of Wales, Bangor, Gwynedd LL57 2UW, U.K.,Studies of Magnetic Properties of Fine Particlesand their Relevance to Materials Science J.L. Dormann and D. Fiorani (Editors) ã1992 Elsevier Science Publishers B.V.

[23] Amri Saiful Bin Mazlan ,2008, The Behaviour Of Magneto rheological Fluids In Squeeze Mode, A thesis submitted for the degree of Doctor of Philosophy, School of Mechanical and Manufacturing Engineering Faculty of Engineering and Computing Dublin City University.

[24] Velmurugan kandasamy, Sangli Karuppanan Venkatachalapathyb, Vellaiyappan,2009, Thermogravimetric and Magnetic Properties of Ni1-XZnxFe2O4 Nanoparticles Synthesized by Coprecipitation, Sri Chandrasekharendra Saraswathi Viswa Mahavidyalaya University, Kanchipuram - 631561, India School of Biosciences and Bioengineering, Indian Institute of Technology, Mumbai 400076, India. 